\title{
A PRELIMINARY TECHNO-ECONOMIC STUDY ON DYEING POLYAMIDE 6 FABRIC
}

\author{
W. M. RASLAN AND A. BENDAK \\ Textile Research Division, National Research Centre Dokki, Cairo, Egypt
}

\begin{abstract}
Attempts are undertaken to perform a comparative techno-economic investigation of two dyeing methods of polyamide fabrics; a conventional dyeing method normally as applied in industry versus a proposed modified one which depends on the usefulness of chemical pretreatment of polyamide fabric with acetaldehyde or a redox system at ambient conditions. The tensile strength and elongation percentage of the pretreated polyamide 6 fabrics are unchanged by the aforementioned treatments while the dyeability of the pretreated fibres can be enhanced at lower dyeing temperature.

The economic aspects of the dyeing processes are pursued, where the variables are brought together, to determine the production costs. The pretreatment of polyamide 6 with either reagent reveals some improvements in dyeing characteristics. This is reflected on the possibility of saving considerable amount of energy, shortening the time of dyeing, increasing the production rate and so lowering the total cost of the dyeing process as well as reducing the environmental impacts.
\end{abstract}

Keywords: Polyamide, treatment, redox system, aldehyde, techno-economic, dyeability.

\section{Introduction}

Why do polyamide fibres need modified dyeing processes? There are always some needs for productivity improvement, lowering of both overheads and running costs. New considerations are emerging for improved dyeing quality, reduced environmental impacts, reducing the costs of water and other raw materials as well as attaining safety ${ }^{(1)}$.

The response to these considerations is being developed from the traditional and current skill-bases. Pooling of techno-economic knowledge across research and application would improve the productivity when faced by lower cost competition $^{(1)}$. The intention is to achieve lower machinery cost, less chemicals and energy consumption, easier wash-off, better reproducibility and rapid as well as easier technical changes for higher value-added products. New raw materials and 
modified technology are intended to attain high-quality products and getting it right first time and every time.

The cost of energy is continuously increasing and is becoming a significant share of total cost of processing textiles. Dyers should take considerable efforts to minimize energy consumption to conserve energy and to recover energy. There are a lot of opportunities to make wet processing energy efficient to conserve energy. Lowering the dyeing temperature brings down the energy requirements which can be done by employing some dyebath additives or by giving some pretreatment to the material to be dyed, during which improvement of the dyeing behaviour of the fibre can be achieved ${ }^{(2)}$.

In this techno-economic approach to dye pretreated polyamide 6 fabrics, attempts are entailed to estimate the total cost of two dyeing methods; a conventional one normally applied in practice and a modified method suggested by inducing a chemical pretreatment step in the course of polyamide- 6 fabric processing. A flow sheet of the modified process is also suggested.

\section{Experimental}

All experiments including the fibre treatment and dyeing process were carried out in large scale. No drying of samples was applied before introducing them to dyebath (i.e. the process is wet on wet).

\section{Materials}

Polyamide 6 (PA-6) fabric was supplied from El-Nasr Spinning, Weaving and Knitting Co., Cairo. Fabric construction is warp 42 ends $/ \mathrm{cm}$, weft 36 picks $/ \mathrm{cm}$. The material was soaped at $70^{\circ} \mathrm{C}$ for $1 \mathrm{hr}$, thoroughly washed and air dried at ambient temperature. Chemicals of pure grade were used vis. acetaldehyde, acetic acid, ethanol, hydrogen peroxide and glyoxal. Commercial dyes C.I. Acid Red1 and C.I. Acid Red 41 were used.

\section{Treatments}

Acetaldehyde treatment

PA-6 fabric was treated with aqueous solutions of acetaldehyde at room temperature, using concentration of $0.2 \mathrm{M}$ for $30 \mathrm{~min}$. at a liquor ratio of $1: 10^{(3)}$.

\section{Glyoxal/ $\mathrm{H}_{2} \mathrm{O}_{2}$ treatment}

The redox system glyoxal/ hydrogen peroxide is applied to assist the dyeing of PA-6 in two ways: the first is by immersing the fabric in glyoxal solution (up to 
$0.5 \mathrm{~g} / 100 \mathrm{~g}$ fibres), at $50^{\circ} \mathrm{C}, 30 \mathrm{~min}$. The aqueous pretreatment medium was partially changed by adding few amounts of ethanol (2:98 ethanol/ water). The samples were then squeezed to pick up $100 \%$ and further introduced to the dyebath containing 1 $\mathrm{ml} \mathrm{H}_{2} \mathrm{O}_{2}$ (35\% / liter). The second way was tried by concurrent treatment with the redox system and dyeing ${ }^{(4)}$. It is worthy to note that glyoxal consumption in case of pretreatment step is one tenth (1/10) of that used in case of adding it in the dyebath ${ }^{(4)}$. The pretreatment step was preferred in this study from an economy and environment point of view.

Dyeing

Conventional exhaust dyeing of PA-6 fabric was performed at nearly the boil ${ }^{(5)}$. Pretreated PA-6 wet fabrics with either acetaldhyde or glyoxal $/ \mathrm{H}_{2} \mathrm{O}_{2}$ were exhaust dyed at different temperatures $\left(60^{\circ}, 70^{\circ}\right.$ and $\left.80^{\circ} \mathrm{C}\right)$. The $\mathrm{pH}$ value of the dyeing bath was adjusted at 4.5 by adding acetic acid (about $1 \mathrm{ml} /$ litre) and using a liq. ratio of $1: 10^{(3,4)}$.

\section{Colour Measurements}

The dye uptake was estimated spectrophotometrically and expressed as (g dye $/ 100 \mathrm{~g}$ fibre). Spectral reflectance measurements of the dyed fabric were carried out using a recording filter spectrophotometer (Perkin - Elmer UV/Vis. Spectrophotometer Model, Lambda 3B). The colour intensity expressed as K/S values of the dyed samples was determined according to the Kubelka-Munk equation ${ }^{(6)}$.

$$
\mathrm{K} / \mathrm{S}=\frac{(\mathrm{I}-\mathrm{R})^{2}}{2 \mathrm{R}}-\frac{\left(\mathrm{I}-\mathrm{R}_{\mathrm{o}}\right)^{2}}{2 \mathrm{R}_{\mathrm{o}}}
$$

Where: $\mathrm{R}$ is the decimal fraction of the reflectance of the dyed sample,

$R_{o}$ is the decimal fraction of the reflectance of the undyed sample,

$\mathrm{K}$ is the absorption coefficient,

$\mathrm{S}$ is the scattering coefficient.

\section{Kinetic Studies}

The values of half-dyeing time $\left(\mathrm{t}_{1 / 2}\right)$, specific dyeing rate constant $(k)$ as well as the diffusion coefficient (D) calculated for the dyed untreated and pretreated PA-6 fabric according to the following equations ${ }^{(7-9)}$. 


$$
k^{\prime}=0.5 C_{\infty}\left(\frac{d}{t_{1 / 2}}\right)^{1 / 2}
$$

$$
\mathrm{D}=\frac{\mathrm{C}_{\mathrm{t}}}{\mathrm{C}_{\infty}} \cdot \frac{100 \mathrm{~d}^{2}}{\mathrm{t}}
$$

Where $\mathrm{C}_{\infty}$ is the dye uptake by the sample at equilibrium, $\mathrm{C}_{t}$ is the dye uptake after $10 \mathrm{~min}$ and $\mathrm{d}$ is the fibre diameter in $\mathrm{cm}$.

The modified Arrhenius relationship was applied to estimate the activation energy of diffusion as follows ${ }^{(10)}$ :

$$
\ln C=\ln C_{o}-\frac{E}{R T}
$$

Where: $\mathrm{C}$ is the dye absorbed after a short dyeing time, $\mathrm{C}_{\mathrm{o}}$ is constant, $\mathrm{T}$ is the absolute dyeing temperature $\left({ }^{\circ} \mathrm{K}\right)$ and $\mathrm{E}$ is the activation energy of diffusion. By plotting $\operatorname{lnC}$ versus $1 / \mathrm{T}$, straight lines are to be given. The slope of the straight line equals $-\mathrm{E} / \mathrm{R}$ from which the activation energy of diffusion (E) can be calculated where $\mathrm{R}$ is the universal gas constant.

\section{Results and Discussion}

Dyeing behaviour of pretreated PA-6 fabric

\section{Acetaldehyde Pretreated fabric}

Fig. 1 illustrates the relation between the dye uptake and the time of dyeing for the untreated PA- 6 dyed by the conventional dyeing method at nearly the boil, the untreated PA- 6 dyed at low temperature $\left(80^{\circ} \mathrm{C}\right)$ and pretreated PA- 6 with acetaldehyde at $80^{\circ} \mathrm{C}$. It can be noticed that PA-6 fabrics had exhausted the same amount attained by conventional dyeing method $(0.92 \mathrm{~g}$ dye $/ 100 \mathrm{~g}$ fibre) after about $45 \min$ at $80^{\circ} \mathrm{C}$.

On the other hand, the concentration of acetaldehyde after PA-6 treatment was found to be approximately constant after $30 \mathrm{~min}$ of treatment. The volume of the treatment solution was found to decrease by amount of ca. 3001 . It was previously noted that the mechanical properties of the pretreated PA-6 fabric were not changed and the fastness properties were found to be reasonable ${ }^{(3,4)}$.

Pretreated PA-6 fabric with glyoxal / $\mathrm{H}_{2} \mathrm{O}_{2}$ redox system

Treatment of PA-6 fabric was tried in two steps (pretreatment followed by dyeing) and in one step by adding glyoxal and hydrogen peroxide to the dyebath. It 
was noticed that the rate of increasing exhaustion $\%$ with increasing the glyoxal concentration is higher in case of using two steps (pretreatment followed by dyeing) than using one step (Fig.2). The two-steps method is found to be slightly better in enhancing the dyeability of PA-6 fabric than using the redox system in one step, beside the lower consumption of glyoxal in case of two steps (1/10 of concentration of glyoxal in one step). The two steps method was undertaken for further cost estimations.

Fig. 3 shows the dependence of dye uptake of pretreated PA-6 fabric with glyoxal/ $\mathrm{H}_{2} \mathrm{O}_{2}$ redox system in two steps on the time of dyeing at different dyeing temperatures. The aqueous pretreatment medium was partially changed by adding few amounts of ethanol (2:98 ethanol/ water). The dyeing behaviour was found to be greatly enhanced by the pretreatment as well as shortening the time of dyeing as compared with the untreated fabric either dyed by conventional method at the boil or dyed at lower temperatures $\left(60^{\circ}, 70^{\circ}\right.$ and $\left.80^{\circ} \mathrm{C}\right)$. It can be noticed that pretreated PA6 fabric exhausts almost completely the dye from the bath at different temperatures $\left(60^{\circ}, 70^{\circ}\right.$ and $\left.80^{\circ} \mathrm{C}\right)$ after about 40,20 and 10 min respectively.

The colour intensity of untreated and pretreated PA-6 fabric with the redox system in ethanol/ water (2:98) mixture is shown in Table 1. It was noticed that there is a significant colour difference between the untreated and pretreated mate dyed at the same conditions.

\section{Kinetic Evaluation}

A physicochemical investigation was carried out on the dyeing behaviour of polyamide 6 with acid dye. Dyeing was carried out for both the untreated fabric dyed at $60^{\circ} \mathrm{C}, 70^{\circ} \mathrm{C}, 80^{\circ} \mathrm{C}$ and at the boil and the pretreated one with redox system dyed at $60^{\circ} \mathrm{C}, 70^{\circ} \mathrm{C}$ and $80^{\circ} \mathrm{C}$. Table 2 shows the values of half dyeing time $\left(\mathrm{t}_{1 / 2}\right)$, dyeing rate constant $\left(\mathrm{k}^{\prime}\right)$ and diffusion coefficient $(\mathrm{D})$. It is apparent that $\mathrm{t}_{1 / 2}$ at $60^{\circ} \mathrm{C}$ decreased by the applied treatment from $14.6 \mathrm{~min}$ for untreated sample to $5.1 \mathrm{~min}$ for glyoxal pretreated sample in ethanol / water mixture (2:98), as compared with the given half dyeing time at $80^{\circ} \mathrm{C}$ which decreased from $5.8 \mathrm{~min}$ to $3.6 \mathrm{~min}$. It was noticed that the half dyeing time $\left(\mathrm{t}_{1 / 2}\right)$ of the pretreated PA- 6 was found to be lower than that of untreated one dyed at nearly the boil (conventional dyeing). It was shown that both the dyeing rate constant (k') and the diffusion coefficient (D) for the pretreated dyed samples at all the applied dyeing temperatures were found to be higher than that of the untreated dyed substrate. 
The activation energy for untreated and pretreated fabric was evaluated by applying Arrhenius equation (Table 3). It decreased from $41.5 \mathrm{~kJ} / \mathrm{g}$ mol for the untreated one to $26.9 \mathrm{~kJ} / \mathrm{g}$ mol for pretreated polyamide 6 fabric with glyoxal $/ \mathrm{H}_{2} \mathrm{O}_{2}$ in ethanol / water.

The decrease in the half dyeing time and the activation energy as well as the increase in the dyeing rate constant and the diffusion coefficient may lead to saving in energy consumption and to an increase of the dye consumption from the dyebath revealing a positive effect on the environmental impacts.

\section{Techno-economic investigation}

A comparative techno-economic investigation is performed on the exhaust dyeing of PA- 6 fabric either for untreated fabric at the boil or at $60^{\circ}, 70^{\circ}$ and $80^{\circ} \mathrm{C}$ for the pretreated ones. This estimation is a preliminary trial before conducting the pilot and/or industrial scales processes.

A survey on the Egyptian market was necessary to have an average price of the chemicals to be used in this work. Table 4 represents the average prices of chemicals and water used in the dyeing process. The price is given in Egyptian Pound (L.E.) according to the running cost in the year 2005-2006.

\section{Cost of Chemicals and water in Conventional dyeing Method.}

The conventional exhaust dyeing was performed using a dyebath containing the dye of shade $1 \%$ o.w.f. ( $1 \mathrm{~g}$ dye / $100 \mathrm{~g}$ fabric). The $\mathrm{pH}$ value was adjusted to 4.5 by adding $1 \mathrm{ml}$ acetic acid and $0.5 \mathrm{~g}$ sodium acetate $/ 1$. The dyeing liquor containing the fabric remained at $40^{\circ} \mathrm{C}$ for $20 \mathrm{~min}$. The temperature was raised to nearly the boil in $30 \mathrm{~min}$ by a rate of $2^{\circ} \mathrm{C} / \mathrm{min}$. Dyeing was further conducted at the boil for $60 \mathrm{~min}{ }^{(5)}$.

It was found that PA-6 fabric had exhausted $92 \%$ of the dye from the bath $(0.92 \mathrm{~g}$ dye / $100 \mathrm{~g}$ fabric). The costs of the elements of the dyeing of about $300 \mathrm{Kg}$ fabric (one cycle) and using liq. ratio of 1:10 can be then evaluated as:

$$
\begin{array}{ll}
\text { Dye }(1 \% \text { o.w.f. }) & =600 \mathrm{LE} \\
\text { Water } & =7.5 \mathrm{LE} \\
\text { Acetic acid } & =31.5 \mathrm{LE} \\
\text { Sodium acetate } & =202.5 \mathrm{LE} \\
\text { Total } & =841.5 \mathrm{LE} / \text { cycle }
\end{array}
$$


Thus the cost of chemicals and water in the dyeing process is $2.8 \mathrm{LE}$ / kilogram of fabric.

Cost of Chemicals and water for Modified Dyeing Method.

Treatment of Polyamide 6 fabric with both acetaldehyde and redox system (glyoxal/ hydrogen peroxide) was found to improve its dyeability with acid dye as well as shortening the time of dyeing ${ }^{(3,4)}$. It is worth to mention that the mechanical properties of the pretreated PA- 6 fabric were unchanged by the aforementioned treatment. The tensile strength was found to be $926 \mathrm{~g}, 927 \mathrm{~g}$ and $924 \mathrm{~g}$ for untreated and pretreated PA-6 fabric with acetaldehyde and redox system respectively, while the elongation $\%$ was found to be $24.8 \%, 24.9 \%$ and $24.5 \%$ respectively.

Also, the washing fastness properties staining (st.) and alteration (alt) were found to be 3-4 for untreated PA-6 fabric corresponding to 4-5 for the pretreated one.

\section{- Acetaldehyde Pretreated fabric}

It was previously mentioned that the concentration of acetaldehyde after PA-6 treatment was found to be approximately constant after $30 \mathrm{~min}$ of treatment. The volume of the treatment solution was found to decrease by amount of ca. $3001^{(3)}$. In this case the evaluation of the cost of chemicals and water/cycle ( $300 \mathrm{Kg}$ fabric) is given as follows:

$$
\begin{array}{ll}
\text { Acid dye }(1 \% \text { o.w.f.) } & =600 \mathrm{LE} / \text { cycle } \\
\text { Water for pretreatment, dyeing and rinse } & =11.625 \mathrm{LE} / \text { cycle } \\
\text { Acetic acid } & =31.5 \mathrm{LE} / \text { cycle } \\
\text { Acetaldehyde } & =435 \mathrm{LE} / \text { cycle } \\
\text { Total costs of chemicals and water } & =1078.125 \mathrm{LE} / \text { cycle }
\end{array}
$$

Thus the cost of chemicals and water in the pretreatment and dyeing processes is 3.6 LE / kilogram of fabric.

-Pretreated PA-6 fabric with glyoxal / $\mathrm{H}_{2} \mathrm{O}_{2}$ redox system

PA-6 fabric was pretreated with glyoxal solution and then squeezed to a pick up ca. $100 \%$ ( $0.5 \mathrm{~g}$ glyoxal $/ 100 \mathrm{~g}$ fibre) and further dyed in dyeing bath containing $\mathrm{H}_{2} \mathrm{O}_{2}$ $(1 \mathrm{ml} / \mathrm{l})$ at different temperatures $\left(60^{\circ}, 70^{\circ}\right.$ and $\left.80^{\circ} \mathrm{C}\right)$ to exhaust nearly completely the dye from the bath after about 40, 20 and 10 min respectively as shown in Fig.3. The dyeing liquor can be reused as the amount of dye in the bath diminished to 
nearly nil; meanwhile colour leveling and homogeneity of the dyed fabric were attained $^{(4)}$.

Fig. 4 shows the proposed flow sheet of the modified dyeing process for the pretreated PA-6 with the redox system. The treatment solution was prepared in the first storage tank and then entered the dyeing machine containing the un-dyed fabric. The pretreatment was done at $50^{\circ} \mathrm{C}$ for $30 \mathrm{~min}$., and then the treatment solution was returned to the storage tank to be used again after its adjustment by adding $(1.5 \mathrm{Kg}$ glyoxal +6 liter ethanol +300 liter water every cycle). The dyebath was prepared in the dye preparation tank and delivered to the dyeing machine containing the wet pretreated fabric with glyoxal where the dyeing process occurred at the predescribed conditions. The dyebath was reused after adjustment (by adding 300 liter water+ $2.76 \mathrm{Kg}$ acid dye (to attain the same dye uptake by the fabric dyed by conventional dyeing method) +3 litre $\mathrm{H}_{2} \mathrm{O}_{2}+0.5$ litre acetic acid). The dyed material was finally washed with water (3000 litre).

The costs of chemicals and water consumed in the pretreatment and dyeing processes matched the up-taken dye by the conventional dyeing method.

The costs of the dyeing elements can be then evaluated as:

$\begin{array}{ll}\text { Acid dye } & =552 \mathrm{LE} / \text { cycle } \\ \text { Glyoxal for pretreatment } & =180 \mathrm{LE} / \text { cycle } \\ \text { Water for pretreatment, dyeing and rinse } & =4.5 \mathrm{LE} / \text { cycle } \\ \text { Acetic acid } & =5.25 \mathrm{LE} / \text { cycle } \\ \text { Ethanol } & =48 \mathrm{LE} / \text { cycle } \\ \mathrm{H}_{2} \mathrm{O}_{2} & =18 \mathrm{LE} / \text { cycle } \\ \text { Total } & =807.85 \quad \mathrm{LE} / \text { cycle }\end{array}$

Thus each kilogram fabric costs $2.7 \mathrm{LE}$ for pretreatment and dyeing.

Table 5 illustrates comparatively the cost of chemicals, dyes and water consumed in the investigated dyeing processes. It can be seen that the case of PA-6 fabric pretreated with glyoxal $/ \mathrm{H}_{2} \mathrm{O}_{2}$ redox system attained the lowest cost and on the other hand acetaldehyde pretreated PA-6 fabric is relatively the highest. Specifically, this held true in the element of water consumption. Pretreated PA-6 fabric with redox system showed the lowest dyeing cost as it was totally exhausted from the dyebath giving rise to minimum impacts on the waste effluents. 


\section{Steam consumption}

The amount of steam required to offer necessary heat to the wet processes can be estimated from the following equation ${ }^{(11)}$ :

$$
\mathrm{Q}=\mathrm{W} \cdot \mathrm{Cp} \cdot \Delta \mathrm{t}
$$

Where $\mathrm{Q}$ is the heat required

$\mathrm{Cp}$ is the specific heat of matter to be warmed up

$\mathrm{W}$ is the weight of the material to be warmed up; and

$\Delta \mathrm{t}$ is the temperature difference involved,

An initial temperature of $20^{\circ} \mathrm{C}$ is assumed for water

The heat loss by radiation and by other means can be calculated by assuming that the total heat is twice the heat required for heating up ${ }^{(12)}$.

\section{-Conventional dyeing}

The required heat $\quad \mathrm{Q}=248640 \mathrm{Kcal}$

Therefore the amount of heat given including losses/cycle $=2 \times 248640$

$$
=497280 \mathrm{Kcal}
$$

\section{-Pretreatment with Acetaldehyde and Dyeing}

a) The pretreatment was carried out at room temperature

b) The dyeing process was performed at $80^{\circ} \mathrm{C}$

Thus the required heat $\mathrm{Q}=186480 \mathrm{Kcal}$

Therefore the heat required including losses/cycle $=372960 \mathrm{Kcal} / \mathrm{cycle}$

- Pretreated with glyoxal $/ \mathrm{H}_{2} \mathrm{O}_{2}$ and Dyeing

a) The pretreatment was carried out at $50^{\circ} \mathrm{C}$ for $30 \mathrm{~min}$

The required heat $=12240 \mathrm{Kcal}$

It has to be noted that the loss due to radiation is considered as $0.15 \mathrm{Q}^{(11)}$.

Therefore the total heat required for the pretreatment/cycle

$$
=12240 \times 1.15=14076 \mathrm{Kcal}
$$

b) The dyeing was conducted at $60^{\circ}, 70^{\circ}$ and $80^{\circ} \mathrm{C}$ for 40,20 and $10 \mathrm{~min}$ respectively to achieve a complete exhaustion with good homogeneity and the 
dyeing liquor can be further reused. Assuming the change in temperature being $40^{\circ}$, $50^{\circ}$ and $60^{\circ} \mathrm{C}$ in case of dyeing at $60^{\circ}, 70^{\circ}$ and $80^{\circ} \mathrm{C}$ respectively.

Therefore the heat required $Q=70320 \mathrm{Kcal}$

A total heat required $/$ cycle at $60^{\circ} \mathrm{C}=154716 \mathrm{Kcal}$

Similarly

Total heat required $/ \mathrm{cycle}$ at $70^{\circ} \mathrm{C}=162876 \mathrm{Kcal} / \mathrm{cycle}$

Total heat required/cycle at $80^{\circ} \mathrm{C}=171036 \mathrm{Kcal} / \mathrm{cycle}$

Table 6 shows the cost of heat energy per kg of fabric. It is clear that the glyoxal / $\mathrm{H}_{2} \mathrm{O}_{2}$ pretreated fabric attained the lowest value.

\section{Fixed Costs}

In addition to the expenditure on dyes, chemicals, water and energy, the layout on the equipment and operating personnel carrying out the dyeing process have to be considered, besides the general costs and overheads. The general costs have to be a common item not to be included in the calculations.

\section{-Machinery}

The suggested dyeing processes have to be compared with the conventional one. The price of Jet machine is considered as one million Egyptian pounds. For suggestion of dyeing methods, a stainless steel tank of $4 \mathrm{~m}^{3}$ volume is required for preparation and storing the pretreatment solutions of either acetaldehyde or glyoxal. A stainless steel pump $(5 \mathrm{Hp})$ is also required. The total cost of the pump and the storage tank is assumed to be about 10.000 LE, supposing the use of two Jet machines in this study.

\section{-Calculation of operating costs}

Calculation of the time required to complete the dyeing cycle, including washing and preparation, is evaluated to be $250 \mathrm{~min}$ for conventional dyeing at the boil and $230 \mathrm{~min}$ for dyeing acetaldehyde pretreated PA-6 fabric as compared to 220, 200 and 185 min for dyeing the pretreated fabric with glyoxal $/ \mathrm{H}_{2} \mathrm{O}_{2}$ at $60^{\circ}, 70^{\circ}$ and $80^{\circ} \mathrm{C}$ respectively. This gives rise to 5, 5.5, 5.5, 6 and 7 cycles / day for the aforementioned dyeing methods respectively.

The capacity / day =

number of dyeing machine $\mathrm{x}$ number of cycles $\mathrm{x}$ (capacity/cycle). 
This achieves ca. $3000 \mathrm{~kg}$ / day for conventional dyeing method and $3300 \mathrm{~kg} / \mathrm{day}$ for dyeing pretreated fabric with acetaldehyde and 3300,3600 and $4200 \mathrm{~kg} /$ day for pretreated fabric with glyoxal $/ \mathrm{H}_{2} \mathrm{O}_{2}$ dyed at $60^{\circ}, 70^{\circ}$ and $80^{\circ} \mathrm{C}$ respectively. This corresponds to 720.000, 792.000, 792.000, 864.000 and $1.008 .000 \mathrm{~kg} / \mathrm{year}$ respectively (by assuming 20 working day/month).

\section{-Depreciation}

Supposing the depreciation for 10 years as:

$$
\frac{1}{10} \times \frac{\text { cost of machine }}{\text { production rate (kg/y ear) }}
$$

\section{-Interest}

Assuming the interest $=10 \%$ of the capital cost.

-Repairs

Assuming that the repairs $=5 \%$ of the capital cost.

-Labour

The labour $/ \mathrm{kg}$ fabric $=($ Man hour $\mathrm{x}$ no. of hours/shift $\mathrm{x}$ no. of shifts/day $\mathrm{x}$ no. of labours/shift) $\div$ (no. of batches/day x Production rate/ batch)

Assuming that the two Jet machines require two persons in all dyeing processes working 3 shifts/ day for 8 hours/shift and then the salary of each person can be calculated to be $480 \mathrm{LE} / \mathrm{month}$.

Table 7 represents the total fixed operating costs/kg fabric for all dyeing processes in this study. It can be noticed that the investigated pretreatments led to decrease the operating costs as well as increasing the production rate.

Table 8 illustrates the total production cost $/ \mathrm{kg}$ fabric. Glyoxal/ $\mathrm{H}_{2} \mathrm{O}_{2}$ pretreated fabric attained a lower production cost than both conventional dyeing method and that pretreated fabric with acetaldehyde. It can be noticed that pretreatment of PA-6 fabric with redox system (glyoxal $/ \mathrm{H}_{2} \mathrm{O}_{2}$ ) led to a decrease in the total production cost/ $\mathrm{kg}$ fabric in the range of $7-11 \%$ as well as increasing the production rate/year and decreasing the pollution impacts without impairing the tensile properties of the fibre as studied elsewhere ${ }^{(4)}$. Pretreatment of PA- 6 fabric with acetaldehyde led to a decrease in energy consumption and an increase in the production rate, but due to the high price of chemicals used in the pretreatment revealed insignificant results. 
Table 1: Colour intensity of untreated and pretreated polyamide 6 fabric.

\begin{tabular}{|c|c|}
\hline Type of Sample & $\begin{array}{l}\text { Colour Intensity } \\
\qquad(\mathrm{K} / \mathrm{S})\end{array}$ \\
\hline 1- Untreated & 4.1 \\
\hline $\begin{array}{l}\text { 2-Pretreated with glyoxal in } \\
\text { ethanol / water }(2: 98)\end{array}$ & 7.5 \\
\hline
\end{tabular}

Table 2: Half dyeing Time $\left(t_{1 / 2}\right)$, dyeing rate constant $\left(K^{\prime}\right)$, and diffusion coefficient (D) of polyamide 6 fibres.

\begin{tabular}{rccc}
\hline \multicolumn{1}{c}{ Type of Sample } & $\mathrm{t}_{1 / 2}(\mathrm{~min})$ & $\mathrm{K}^{\prime} \times 10^{-3}$ & $\begin{array}{c}\mathrm{D} \\
\left(\mathrm{cm}^{2} \mathrm{sec}^{-1}\right) \times 10^{-5}\end{array}$ \\
\hline -Untreated PA-6 and dyed at $60^{\circ} \mathrm{C}$ & 14.6 & 1.278 & 1.6854 \\
$70^{\circ} \mathrm{C}$ & 6.2 & 2.49 & 2.821 \\
$80^{\circ} \mathrm{C}$ & 5.8 & 2.906 & 3.185 \\
-Untreated PA-6 and dyed at the boil & 5.5 & 3.193 & 3.206 \\
-Pretreated PA-6 and dyed at $60^{\circ} \mathrm{C}$ & 5.1 & 3.604 & 3.244 \\
$70^{\circ} \mathrm{C}$ & 4.4 & 3.88 & 3.792 \\
$80^{\circ} \mathrm{C}$ & 3.6 & 4.29 & 4.2135 \\
\hline
\end{tabular}

Treatment: $0.5 \mathrm{~g}$ glyoxal/ 100g fibre, ethanol/ water ratio (2:98), 50ءC, $30 \mathrm{~min}$.

Dyeing: $1 \%$ (o.w.f.) C. I. Acid Red 41, pH 4.5, liq. ratio 1: 10, $0.1 \% \mathrm{H}_{2} \mathrm{O}_{2}$

Table 3: Activation energy (E) for dyed untreated and pretreated PA-6 fibres.

\begin{tabular}{lc}
\hline \multicolumn{1}{c}{ Type of Sample } & $(\mathrm{E}) \mathrm{kJ} / \mathrm{g} \mathrm{mol}$ \\
\hline 1- Untreated & 41.5 \\
2- Pretreated with glyoxal in & \\
ethanol / water (2:98) & 26.9 \\
\hline
\end{tabular}

Treatment: $0.5 \mathrm{~g}$ glyoxal / $100 \mathrm{~g}$ fibre, ethanol/water ratio (2: 98), $500^{\circ} \mathrm{C}, 30 \mathrm{~min}$.

Dyeing: $1 \%$ (o.w. f.) C. I. Acid Red 41, pH 4.5, liq. ratio 1: 10, $0.1 \% \mathrm{H}_{2} \mathrm{O}_{2}$ 
A PRELIMINARY TECHNO-ECONOMIC STUDY ON DYEING ..... 97

Table 4: The average prices of chemicals and water used in the dyeing process 2006)

\begin{tabular}{lc}
\hline \multicolumn{1}{c}{ Item } & Price (LE) \\
\hline Acid dye & $200 / \mathrm{kg}$ \\
Acetic acid & $10.5 / \mathrm{L}$ \\
Sodium acetate & $135 / \mathrm{kg}$ \\
Glyoxal & $150 / \mathrm{L}$ \\
Ethanol & $8 / \mathrm{L}$ \\
Hydrogen peroxide & $6 / \mathrm{L}$ \\
Water & $1.25 / \mathrm{m}^{3}$ \\
Acetaldehyde & $145 / \mathrm{L}$ \\
\hline
\end{tabular}

Table 5: The costs of chemicals and water consumed $/ \mathrm{kg}$ fabric

\begin{tabular}{ccccc}
\hline \multicolumn{1}{c}{ Dyeing Process } & $\begin{array}{c}\text { Dye } \\
\mathrm{LE} / \mathrm{kg}\end{array}$ & $\begin{array}{c}\text { Chemicals } \\
\mathrm{LE} / \mathrm{kg}\end{array}$ & $\begin{array}{c}\text { Water } \\
\mathrm{LE} / \mathrm{kg}\end{array}$ & $\begin{array}{c}\text { Total } \\
\mathrm{LE} / \mathrm{kg}\end{array}$ \\
\hline $\begin{array}{l}\text { 1-Conventional dyeing at the boil. } \\
\text { 2-Dyeing of pretreated fibre with }\end{array}$ & 2.0 & 0.78 & 0.025 & 2.805 \\
$\begin{array}{c}\text { acetaldehyde. } \\
\text { 3-Dyeing of pretreated fibre with redox } \\
\text { system (glyoxal } / \mathrm{H}_{2} \mathrm{O}_{2} \text { ). }\end{array}$ & 2.0 & 1.555 & 0.039 & 3.594 \\
\hline
\end{tabular}

Table 6: Cost of energy consumption for the different dyeing process in LE/kg fabric

\begin{tabular}{|c|c|c|c|c|}
\hline \multicolumn{2}{|c|}{ Dyeing process } & $\begin{array}{c}\text { Energy/cycle } \\
\text { Kcal }\end{array}$ & $\begin{array}{c}\text { Cost/cycle } \\
\text { LE }\end{array}$ & $\begin{array}{l}\text { Cost } / \mathrm{kg} \\
\mathrm{LE} / \mathrm{kg}\end{array}$ \\
\hline \multicolumn{2}{|c|}{ 1- Conventional dyeing Method } & 497280 & 29.8368 & 0.0995 \\
\hline \multirow{2}{*}{\multicolumn{2}{|c|}{$\begin{array}{l}\text { 2-Pretreated with acetaldehyde. } \\
\text { 3-Pretreated with glyoxal/ } \mathrm{H}_{2} \mathrm{O}_{2}\end{array}$}} & 372960 & 22.3776 & 0.0746 \\
\hline & & & & \\
\hline \multirow[t]{3}{*}{ and dyed at } & $60^{\circ} \mathrm{C}$ & 154716 & 9.283 & 0.031 \\
\hline & $70^{\circ} \mathrm{C}$ & 162876 & 9.772 & 0.0325 \\
\hline & $80^{\circ} \mathrm{C}$ & 171036 & 10.262 & 0.034 \\
\hline
\end{tabular}

Assuming that $10^{6} \mathrm{Kcal}$ energy $=60 \mathrm{LE}$ 
Table 7: Fixed operating costs in LE/kg fabric

\begin{tabular}{|c|c|c|c|c|c|c|}
\hline \multicolumn{2}{|c|}{ Dyeing process } & \multirow{2}{*}{$\begin{array}{c}\text { Depreciation } \\
0.278\end{array}$} & \multirow{2}{*}{$\begin{array}{l}\text { Interest } \\
0.278\end{array}$} & \multirow{2}{*}{$\begin{array}{c}\text { Repairs } \\
0.139\end{array}$} & \multirow{2}{*}{$\begin{array}{c}\text { Labour } \\
0.048\end{array}$} & \multirow{2}{*}{$\begin{array}{l}\text { Total } \\
0.743\end{array}$} \\
\hline $\begin{array}{l}\text { 1-Conventional } \\
\text { Method }\end{array}$ & dyeing & & & & & \\
\hline $\begin{array}{l}\text { 2-Pretreated } \\
\text { acetaldehyde }\end{array}$ & with & 0.255 & 0.255 & 0.127 & 0.044 & 0.681 \\
\hline \multirow{2}{*}{\multicolumn{7}{|c|}{$\begin{array}{l}\text { 3-Pretreated with glyoxal / } \\
\qquad \mathrm{H}_{2} \mathrm{O}_{2} \text { and dyed at }\end{array}$}} \\
\hline & & & & & & \\
\hline & $60^{\circ} \mathrm{C}$ & 0.255 & 0.255 & 0.127 & 0.044 & 0.681 \\
\hline & $70^{\circ} \mathrm{C}$ & 0.234 & 0.234 & 0.117 & 0.04 & 0.625 \\
\hline & $80^{\circ} \mathrm{C}$ & 0.2 & 0.2 & 0.1 & 0.034 & 0.534 \\
\hline
\end{tabular}

Table 8: Production costs in LE/kg fabric

\begin{tabular}{|c|c|c|c|c|c|}
\hline \multicolumn{2}{|c|}{ Dyeing process } & \multicolumn{2}{|c|}{$\begin{array}{l}\text { Variable cost } \\
\text { LE/kg }\end{array}$} & \multirow{2}{*}{$\begin{array}{c}\text { Fixed cost } \\
\text { LE/kg }\end{array}$} & \multirow{2}{*}{$\begin{array}{l}\text { Total } \\
\text { LE/kg }\end{array}$} \\
\hline & & $\begin{array}{l}\text { Chemicals } \\
\text { and Water }\end{array}$ & Energy & & \\
\hline $\begin{array}{l}\text { 1-Conventional } \\
\text { Method }\end{array}$ & dyeing & 2.805 & 0.0995 & 0.743 & 3.65 \\
\hline $\begin{array}{l}\text { 2-Pretreated with } \\
\text { acetaldhyde }\end{array}$ & & 3.594 & 0.0746 & 0.681 & 4.35 \\
\hline \multicolumn{6}{|c|}{ 3-Pretreated with glyoxal/ } \\
\hline \multicolumn{6}{|c|}{$\mathrm{H}_{2} \mathrm{O}_{2}$ and dyed at } \\
\hline & $60^{\circ} \mathrm{C}$ & 2.692 & 0.031 & 0.681 & 3.4 \\
\hline & $70^{\circ} \mathrm{C}$ & 2.692 & 0.0325 & 0.625 & 3.35 \\
\hline & $80^{\circ} \mathrm{C}$ & 2.692 & 0.034 & 0.534 & 3.26 \\
\hline
\end{tabular}




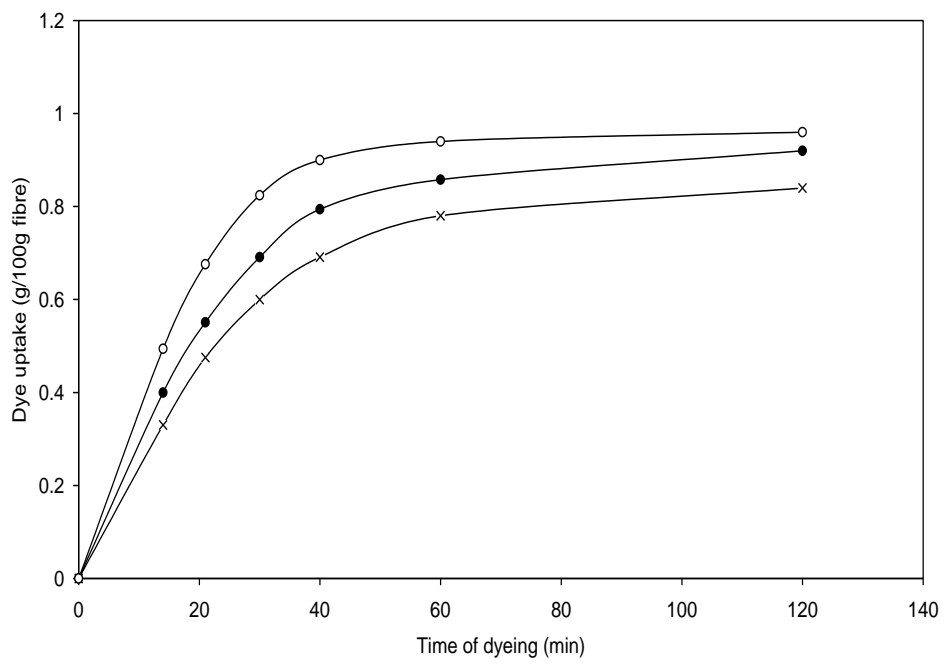

Fig. 1: Dyeability of pretreated polyamide 6 with acetaldehyde in relation to time of dyeing. Treatment: $0.2 \mathrm{M}, 25^{\circ} \mathrm{C}, 30 \mathrm{~min}$., liq. ratio 1:10.

Dyeing: 1\% (o.w.f.) C.I. Acid Red 41, pH 4.5, liq. ratio 1:10 $x-x$ untreated PA -6 and dyed at $80^{\circ} \mathrm{C}$, $\bullet-\bullet$ untreated PA-6 and dyed at $\sim 100^{\circ} \mathrm{C}$, o-o pretreated PA-6 with acetaldehyde and dyed at $80^{\circ} \mathrm{C}$.

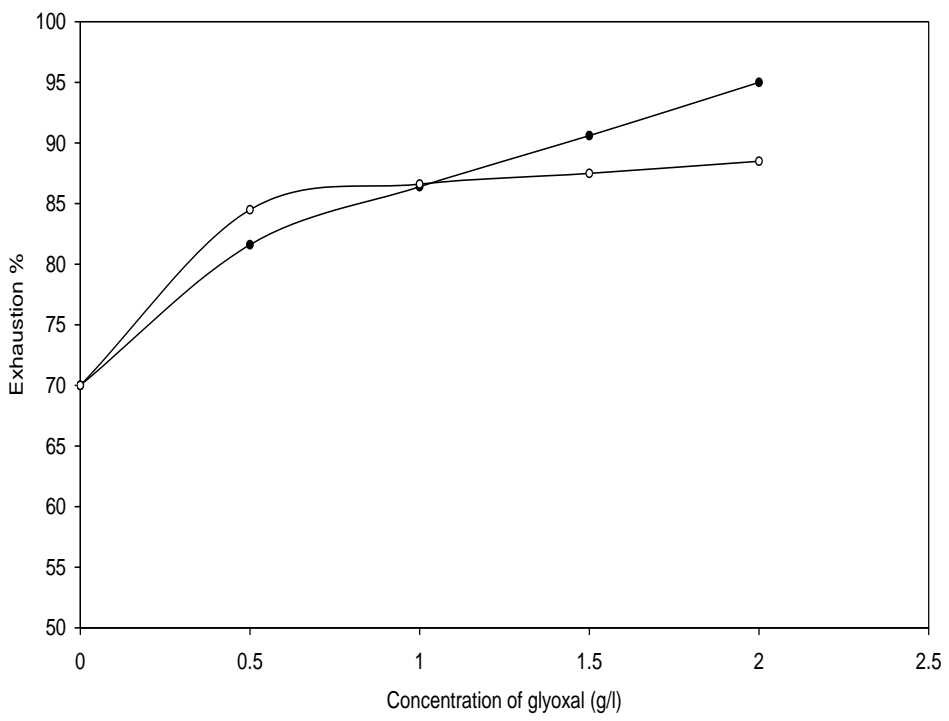

Fig. 2: Dependence of dyeability of PA-6 fabric on concentration of glyoxal.

Treatment: $100 \%$ pick up, $50^{\circ} \mathrm{C}, 30 \mathrm{~min}$.

Dyeing: $2 \%$ (o.w.f.) C.I. Acid Red 1, 0.1\% $\mathrm{H}_{2} \mathrm{O}_{2}, 70^{\circ} \mathrm{C}, 60 \mathrm{~min}, \mathrm{pH} \mathrm{4.5}$, liq. ratio 1:10, $\bullet-\bullet 2$ steps (pretreatment + dyeing), o-o 1 step (treatment and dyeing in the dyebath). 


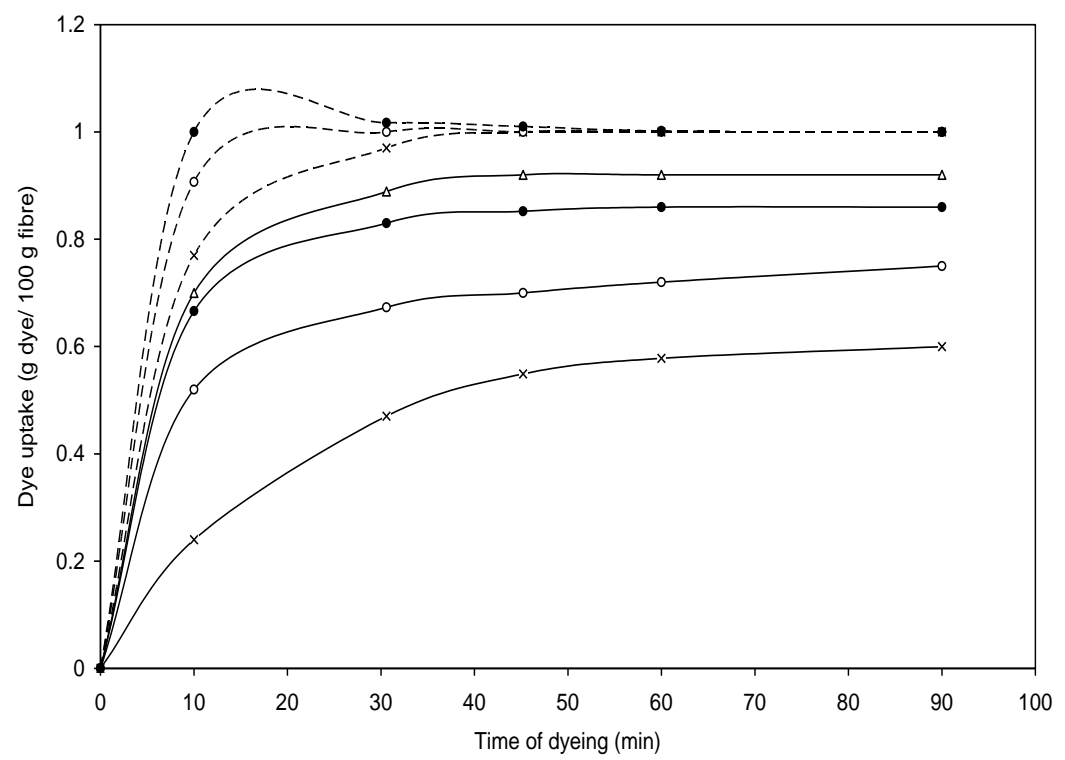

Fig. 3: Dyeing behaviour of pretreated polyamide- 6 fibres with glyoxal/ $\mathrm{H}_{2} \mathrm{O}_{2}$ redox system at different dyeing temperatures.

Treatment: $0.5 \mathrm{~g}$ glyoxal/100g fibres in ethanol/water mixture (2:98), pick up $100 \%, 50^{\circ} \mathrm{C}, 30 \mathrm{~min}$., untreated PA-6, _ _ Pretreated PA-6

Dyeing: $1 \%$ (o.w.f.) C.I. Acid Red 41, pH 4.5, liq. ratio 1: 10, $\mathrm{x}-\mathrm{x} 60^{\circ} \mathrm{C}, 0-07^{\circ} \mathrm{C}, \bullet-\bullet 80^{\circ} \mathrm{C}, \Delta-\Delta 100^{\circ} \mathrm{C}$

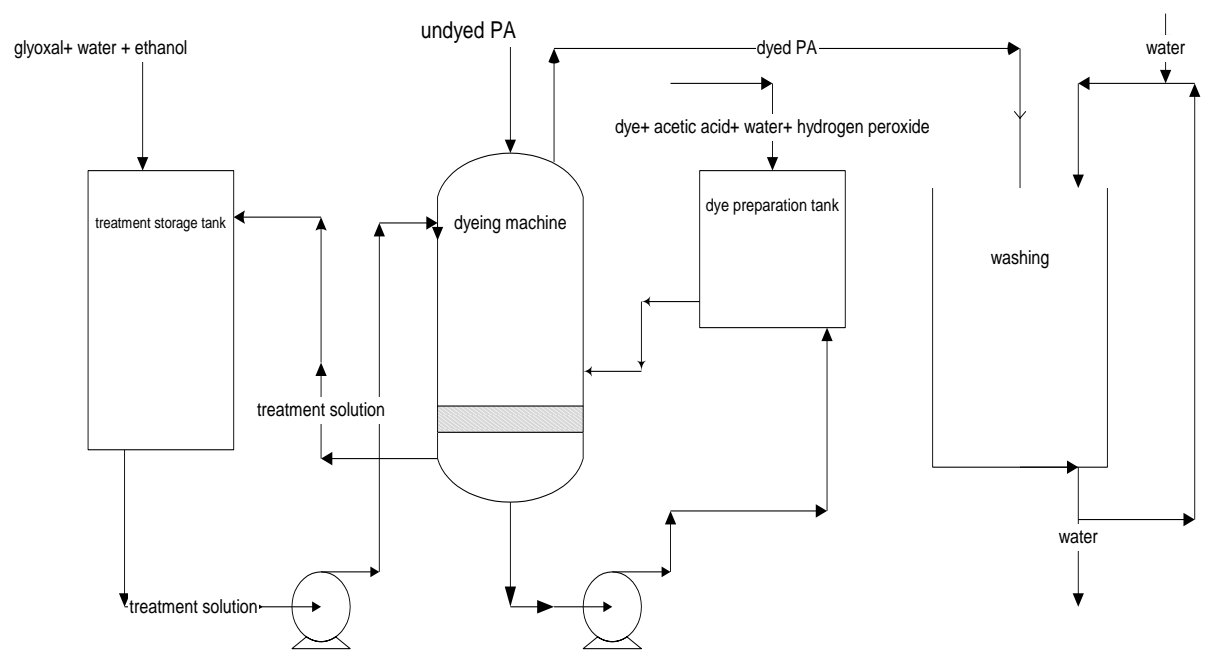

Fig. 4: Proposed flow sheet of the modified dyeing process of pretreated PA-6 fabric with redox system (glyoxal/ $\left.\mathrm{H}_{2} \mathrm{O}_{2}\right)$ 


\section{Conclusion}

It can be concluded that pretreatment of PA-6 fabric with redox system (glyoxal / $\mathrm{H}_{2} \mathrm{O}_{2}$ ) resulted in some improvement in dyeing characteristics, as reflected on saving considerable amount of energy, reducing water consumption, shortening the time of dyeing, increasing the production rate and thus lowering the total cost of dyeing process without any negative effect on the environment or dyeing quality.

\section{References}

1. J. FLOWER, R. BURLEY AND J. NOBBS, J. Soc. Dyers Col., 110, 167 (1994).

2. B. MURALIDHARAN, AND N. T. NEVADITHA, Colourage, 42, 27 (1995).

3. A. KANTOUCH, A. BENDAK AND W. M. RASLAN, J. Soc. Fibre Sci and Tec., Tokyo, 57, 39 (2001).

4. W. M. RASLAN, Tinctoria, 4, 28 (2003).

5. J. R. ASPLAND "Textile Dyeing and Coloration ", AATCC, USA, (1997).

6. D. JUDD AND G. WYSZECKI, "Colour in Business, Science and Industry", John Wiley \& Sons, New York, (1999).

7. K. JOHNSON, "Dyeing of Synthetic Fibres, Recent Development, Nyoes Data Corp., New, Jersey, London, (1974).

8. A. BENDAK, Dyes and Pigments, 11, 233, (1989).

9. A. BENDAK, A. KANTOUCH, S. E. SHALABY AND A. M. RAMADAN, Dyes and Pigments, 13, 205, (1990).

10. G. ALBERTI, A. GERNIANI AND R. D. GIORGI, Annali di Chimica, 74, 429, (1984).

11. R. Weast. Ed., "Hand book of Chemistry and Physics", $57{ }^{\text {th }}$ Edition, CRC Press Inc. (1977).

12. F. C. VILBRANDT AND C. E. DRYDEN, "Chemical Engineering, Plant Design", $4^{\text {th }}$ Ed., McGraw-Hill Kogatusha Ltd., Tokyo, 1959 